\title{
TEMPERATURE AT THE TOOL-CHIP INTERFACE IN CRYOGENIC AND DRY TURNING OF AISI 4340 USING CARBIDE TOOL
}

\author{
Natasha, A. R..$^{* * *}$; Ghani, J. A. ; Che Haron, C. H. ${ }^{*}$; Syarif, J. ${ }^{* * *} \&$ Musfirah, A. H. ${ }^{*}$ \\ ${ }^{*}$ Department of Mechanical and Materials Engineering, Faculty of Engineering and Built \\ Environment, Universiti Kebangsaan Malaysia, 43600 Bangi, Malaysia \\ ** Department of Manufacturing and Materials, Faculty of Engineering, International Islamic \\ University Malaysia, P.O. Box 10, 50728 Kuala Lumpur, Malaysia \\ *** Department of Mechanical Engineering, College of Engineering, University of Sharjah, \\ P.O. Box 27272, Sharjah, United Arab Emirates \\ E-Mail: natashar@iium.edu.my, jaharah@eng.ukm.my, chase@eng.ukm.my, \\ sjunaidi@sharjah.ac.ae, musfirah_abdulhadi@yahoo.com
}

\begin{abstract}
A localized high temperature area occurring at the tip of the tool during a cutting process can be detrimental and lead to a rapid wear mechanism. This paper presents the effect of a cryogenic application during the machining process on the temperature generated at the tool-chip interface, compared to a dry environment in the turning of the AISI 4340 alloy steel using a coated carbide tool. The cutting temperature was estimated using the Third Wave AdvantEdge software, which then was validated with the turning experiments. A significant reduction of the cutting temperature and the steeper temperature gradients on the cutting edge and the chips were observed in the cryogenic machining, which indicates more effective heat removal from the cutting zone. The sudden cold of $-196{ }^{\circ} \mathrm{C}$ caused the chips to become hard and brittle, which enhanced the chip breakability during the machining process.

(Received in February 2015, accepted in November 2015. This paper was with the authors 2 months for 2 revisions.)
\end{abstract}

Key Words: Cryogenic, Heat Transfer Coefficient, Temperature Gradient, Finite Element Analysis

\section{INTRODUCTION}

The heat generated during a metal cutting process is closely related to the deformation and shearing of the work material upon contact with the cutting insert. There are three important zones which are exposed to high strain and consequently become a heat source to the temperature rise of the cutting insert. This high temperature results from the shearing, cutting and rubbing processes that occur throughout the machining process. In Fig. 1, Abukhshim et al. [1] illustrated the heat dissipation from primary, secondary and tertiary deformation zones and the effect of this heat movement on the cutting insert. The main source of heat comes from the secondary deformation zone, which occurs directly on the chip-tool interface. Meanwhile, the heat dissipation from the primary deformation zone, which takes place at the shear plane area, is responsible for the temperature rise of the chips and the cutting insert by the convection flow through the chip-tool interface. The heat generated in the tertiary deformation zone is highly influenced by the tool flank wear. Therefore, as the tool flank wear progresses, the temperature rise in this zone also increases.

The importance of investigating the heat source during metal cutting is to assist in the identification of the best possible method to reduce the temperature generated during the machining process. Cutting fluid has been broadly known to function as a heat removal medium and is applied during the metal cutting. Hence, a comprehensive understanding of the heat source locations provides the researchers with the advantageous ability to predict the accurate technique in applying the cutting fluid in a machining process. 


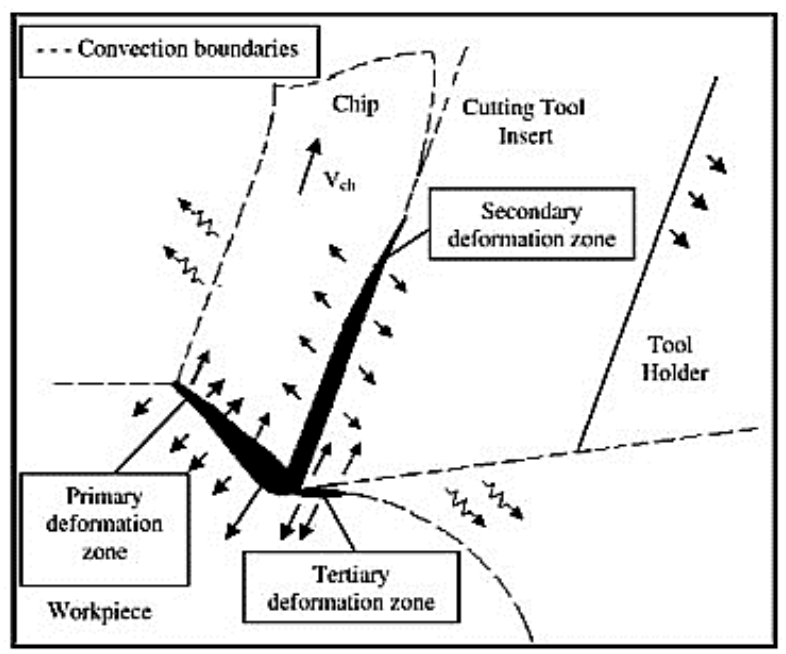

Figure 1: Schematic illustration of a heat transfer model in orthogonal metal cutting [1].

The study of the heat generated at the cutting zone is crucial because of the impact it has on all machining responses. It has been proven that reducing the temperature at the critical zone during the cutting process may result in the excellent performance of the cutting tool, as well as enhance the surface integrity of the work material [2-8]. One of the methods used to lower the temperature during machining is through the application of liquefied cryogenic gasses, such as liquid nitrogen and liquid carbon dioxide. However, the effectiveness of the cryogenic application in reducing the temperature at the tip of the cutting insert is very hard to prove or determine. Among the common approaches to investigate this type of concern is the use of the Finite Element Analysis (FEA) software. FEA has been widely used by researchers to predict the temperature generated at the cutting zone during machining processes [9-12].

However, in order to obtain accurate simulation results for the machining operation with coolant application, heat transfer coefficient $(h)$ is among the important parameters that need to be determined and inputted into the software prior to the simulation [13]. A number of researches have been conducted on predicting the machining outputs with the application of coolant using FEA software. Davoudinejad et al. [13] used the Third Wave AdvantEdge to validate the chip formation and cutting forces in the dry and cryogenic turning of Ti-6Al-4V titanium alloy. The authors tested a few values of $h$ selected based on their literature. They finally set the $h$ to $2000 \mathrm{~kW} /\left(\mathrm{m}^{2} \mathrm{~K}\right)$ since it gave the most accurate simulation results as compared to the experimental test, however they stated that the value was overestimated with respect to reality. In another work, Pu et al. [14] tried a few different values of $h$ and claimed that they obtained a good agreement between the predicted and measured temperatures in the cryogenic machining of AZ31B magnesium alloy when the $h$ value was set to 5000 $\mathrm{kW} /\left(\mathrm{m}^{2} \mathrm{~K}\right)$. Hong and Ding [15] experimentally estimated their $h$ value of a parallel LN flow to be between $4.827 \times 10^{4}$ and $7.495 \times 10^{-4} \mathrm{~W} /\left(\mathrm{m}^{2} \mathrm{~K}\right)$, relying on the surface temperature which was changed from $-180^{\circ} \mathrm{C}$ to $650^{\circ} \mathrm{C}$ when modelling the cryogenic machining of AISI 1008 low carbon steel.

In this paper, the value of the heat transfer coefficient used in the simulation was calculated based on the flow rate of the LN applied during the experimental test. The values of cutting temperature and cutting forces predicted by the FEA were then being compared to the measured values during the experimental works in order to see the reliability of the calculated $h$ value. Besides, the focus of the present paper is to provide better insight into the tribological effect of a cryogenic application during the machining process on the temperature generated at the tool-chip interface, compared to a dry environment in the turning of AISI 4340 alloy steel using a coated carbide tool via a comparative investigation between the FEA simulation and the experimental results. 


\section{EXPERIMENTAL TEST SETUP}

The AISI 4340 used as the work material in this research is a high strength low alloy steel widely used in the automotive and aerospace industries, mainly manufactured as heavy duty shafts, gears, axles, spindles, couplings and pins, as well as some other parts. An AISI 4340 round bar with $100 \mathrm{~mm}$ initial diameter was turned in two separate tests on a TORNADO CNC lathe machine with the capability of $6000 \mathrm{rpm}$ maximum spindle speed. The experimental tests were carried out using coated carbide inserts and the details of the tests are listed in Table I. The chemical compositions of the AISI 4340 alloy steel are presented in Table II. For the cryogenic delivery setup, a flexible hose was connected to the cylindrical liquid nitrogen (LN) tank and a copper pipe was used as a nozzle pointing to the cutting zone as shown in Figs. 2 a, and $2 \mathrm{~b}$ shows the schematic diagram of the cryogenic delivery setup with all the hose and pipe details, as well as the pressure readings. This diagram was sketched using the SketchUp 2015 software. The distance between the tip of the nozzle to the cutting point was fixed at $2 \mathrm{~cm}$.

Table I: Details of experimental test of AISI 4340 alloy steel.

\begin{tabular}{|l|l|}
\hline Item & Description \\
\hline Work material & AISI 4340 alloy steel \\
\hline Cutting inserts & CNMG 120408N-MX \\
Tool Holder & DCLNR 2020K12 \\
Rake angle $\left(^{\circ}\right)$ & -6 \\
Lead angle $\left(^{\circ}\right)$ & -5 \\
\hline Cutting speed (m/min) & 120 \\
\hline Feed (mm/rev) & 0.3 \\
\hline Depth of cut & 1.0 \\
\hline Cutting fluid & Dry and cryogenic (LN) \\
\hline
\end{tabular}

Table II: Chemical composition of AISI 4340 alloy steel.

\begin{tabular}{|l|c|c|c|c|c|c|c|c|c|}
\hline Alloy & $C$ & $S i$ & $M n$ & $P$ & $S$ & $N i$ & $C r$ & $M o$ & $C u$ \\
\hline Wt. \% & 0.4 & 0.22 & 0.65 & 0.019 & 0.017 & 1.7 & 0.76 & 0.21 & 0.11 \\
\hline
\end{tabular}

The debris from the experimental runs were collected and photographed using the Olympus stereo microscope SZ61 with a magnification range of $6.7 \times-45 \times$. They were then analysed in terms of their shape, type and thickness, so as to compare with the chip formed in the simulation runs.
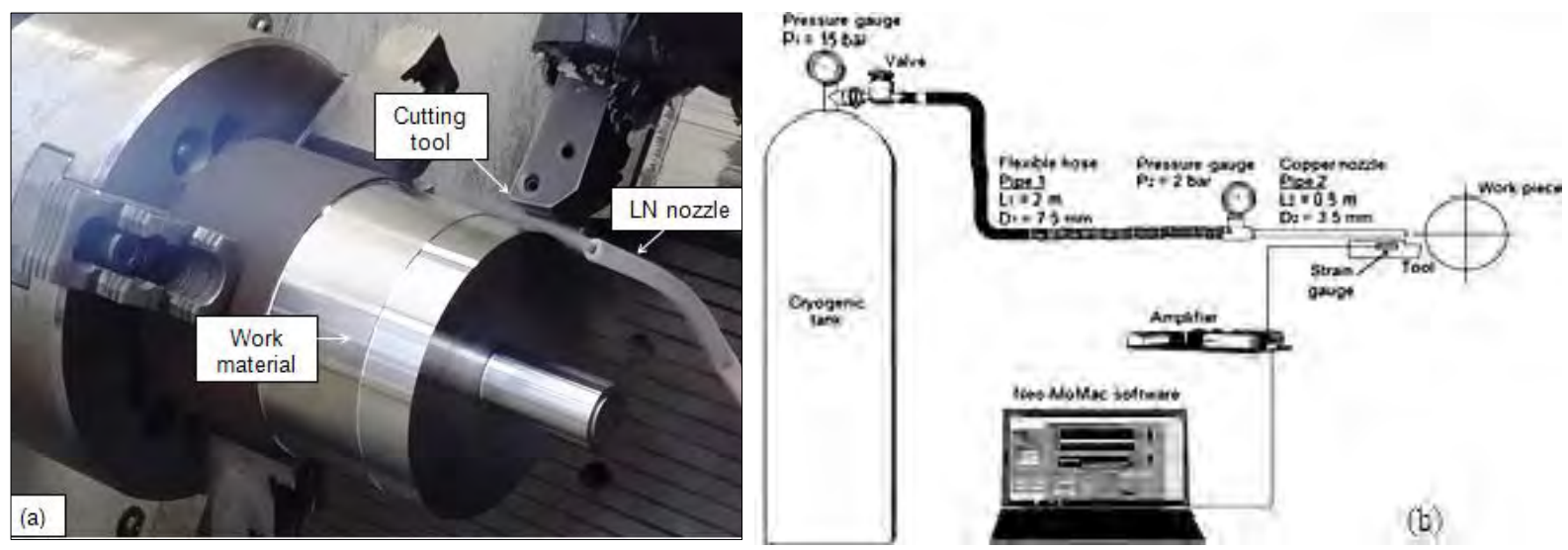

Figure 2: Cryogenic delivery setup showing: a) nozzle pointing to the cutting zone, and b) schematic diagram of cryogenic delivery setup in experimental test. 
During the experimental tests, the cutting temperature was measured using an NEC thermal infrared camera which was positioned at a 1-metre range distance from the point needed to be measured. In the meantime, the Neo-MoMac software was used to measure the cutting forces generated during the cutting operation.

\section{FINITE ELEMENT SIMULATION SETUP}

The commercial FEA software Third Wave AdvantEdge (v6.4) was used to simulate the turning process in a two dimensional (2D) modelling. The main machining response that was examined for this paper was the temperature distribution at the tip of the cutting insert, which includes rake and flank face areas, as well as the temperature gradient on the chip formed during the cutting.

The workpiece was meshed for a maximum number of 24000 nodes. The maximum and minimum element sizes for both workpiece and insert were set at $0.1 \mathrm{~mm}$ and $0.02 \mathrm{~mm}$, respectively. The mesh refinement factor was set at the value of 2 and the coarsening factor was set at 6 . Cutting edge radius fraction and feed fraction were set at 0.6 and 0.1 , respectively. The friction coefficients used in this simulation were adapted from a previous research in [16], which were 0.3 for dry and 0.08 for cryogenic machining.

The machining inputs entered prior to the simulation were equivalent to the machining conditions used in the experimental tests. However, for the cryogenic machining simulation, the user needs to determine the value of the heat transfer coefficient of the coolant being used. The two sub-sections below explain in detail the procedure for calculating the flow rate of the LN delivered by the system, and subsequently the calculation of the $h$ of the LN during the machining process.

\subsection{Flow rate calculation}

The value of the $h$ of the LN delivered during the cutting process depends on the flow rate or flow speed of the liquid at its contact point with the work piece hot surface. Therefore, determining the precise flow speed by using the correct steps of calculation as shown in an article by Shankar Subramanian from Clarkson University, entitled Pipe Flow Calculations, is important to get an accurate value of $h$. The volumetric flow rate, $Q$, of a liquid flowing in a circular pipe can be calculated as in Eq. (1):

$$
Q=V A
$$

where $V$ is the flow speed of the fluid and $A$ is the cross-sectional area of the pipe which was calculated by using the measured value of the pipe diameter, $D$. Since the value of the fluid's velocity in the pipe is unknown, it is connected through the Reynolds number, $R e$, equation as expressed below:

$$
R e=\frac{D V}{V}
$$

where $v$ is the kinematic viscosity of the $\mathrm{LN}$ which is dependent on the temperature and can be acquired by using Eq. (3):

$$
V=\frac{\mu}{\rho}
$$

where $\mu$ is the dynamic viscosity of the $\mathrm{LN}$ and $\rho$ is the density of the LN; both are also dependent on the temperature. The unknown velocity is also related to the friction factor, $f$, and the known pressure drop along the pipe, $\Delta P$, through Eq. (4) below:

$$
\Delta P=2 f\left[\frac{L}{D}\right]\left(\rho V^{2}\right)
$$


where $L$ is the length of the pipe. The friction factor is interrelated with the Reynolds number in the Colebrook equation, which is valid for a turbulent flow. The LN flow is always associated with a turbulent flow due to its small value of viscosity [11]:

$$
\frac{1}{\sqrt{f}}=-4.0 \log _{10}\left(\frac{\varepsilon / D}{3.7}+\frac{1.26}{\operatorname{Re} \sqrt{f}}\right)
$$

where the relative roughness of the pipe can be calculated by using the value of the absolute roughness of the pipe, $\varepsilon$, which is dependent on the material of the pipe's wall and can be widely obtained from the mechanical handbook:

$$
\text { relative roughness }=\frac{\varepsilon}{D}
$$

Since the diameter of pipe 2 is smaller than pipe $1\left(D_{1}>D_{2}\right)$, therefore, by applying the concept of Bernoulli's continuity equation, the flow speed of the $\mathrm{LN}$ in pipe $2, V_{2}$, can be calculated. All the values derived from above calculations are tabulated in Table III below.

Table III: Estimated flow rate of liquid nitrogen used in the experimental test.

\begin{tabular}{|c|c|c|}
\hline $\begin{array}{c}\text { Volumetric flow rate, } \boldsymbol{Q} \\
\left(\mathrm{m}^{3} / \mathrm{s}\right)\end{array}$ & $\begin{array}{c}\text { Flow speed in pipe 1, } \boldsymbol{V}_{\mathbf{1}} \\
(\mathrm{m} / \mathrm{s})\end{array}$ & $\begin{array}{c}\text { Flow speed in pipe 2, } \boldsymbol{V}_{\mathbf{2}} \\
(\mathrm{m} / \mathrm{s})\end{array}$ \\
\hline $1.147 \times 10^{-3}$ & 25.95 & 119.22 \\
\hline
\end{tabular}

\subsection{Heat transfer coefficient calculation}

To calculate the value of $h$ of the LN at the machined surface, a few dimensionless values, namely the Prandtl number, $P r$, Reynolds number, $R e$, and Nusselt number, $N u$, need to be calculated:

$$
\begin{aligned}
& \operatorname{Pr}=\frac{\mu c_{p}}{k} \\
& R e=\frac{\rho V D}{\mu}
\end{aligned}
$$

where $c_{p}$ is the specific heat capacity and $k$ is the thermal conductivity of the LN. For the Nusselt number, the correlation for the forced convective heat transfer over a rotating cylindrical surface to fluid, as shown in Eq. (9) below, was used [17]:

$$
N u=0.1075 \operatorname{Pr}^{0.35}\left(0.5 \operatorname{Re}_{r}^{2}+R e_{t}^{2}\right)^{0.35}
$$

where $R e_{r}$ is the Reynolds number calculated based on the work piece rotation velocity, and $R e_{t}$ is the Reynolds number which takes into account the flow speed of the cutting fluid.

Then, the value of $h$ can be computed from the equation:

$$
h=N u \frac{k}{D}
$$

From the above calculations, the estimated value of the $h$ of the LN used in the finite element simulation in this research is summarized in Table IV.

Table IV: Estimated value of heat transfer coefficient $(h)$ used in the simulation.

\begin{tabular}{|c|c|c|c|c|}
\hline Prandtl & \multicolumn{2}{|c|}{ Reynolds number } & Nusselt & Heat transfer coefficient, \\
\cline { 2 - 3 } number, $\boldsymbol{P r}$ & $\boldsymbol{R e}_{\boldsymbol{r}}$ & $\boldsymbol{R} \boldsymbol{e}_{\boldsymbol{t}}$ & number, $\boldsymbol{N u}$ & $\boldsymbol{h}\left(\mathrm{W} / \mathrm{m}^{2} \cdot \mathrm{K}\right)$
\end{tabular}




\section{RESULTS AND DISCUSSION}

The isothermal contours of the temperature distributions for dry and cryogenic cooling conditions are shown in Fig. 3. For both cutting conditions, the highest temperature always occurs around the middle tool-chip contact area on the rake face, which can be associated with the secondary deformation zone that has been identified as the main source of the temperature rise on the cutting insert [1]. For the dry cutting (Fig. 3 a), the highest temperature generated reached more than $600{ }^{\circ} \mathrm{C}$, much higher than the highest temperature generated in the cryogenic machining which is predicted to be less than $350{ }^{\circ} \mathrm{C}$ as shown in Fig. $3 \mathrm{~b}$. The reason that high temperature was still generated in the cryogenic machining is most probably due to the difficulty of the LN to penetrate into the metallic contact of the chiptool interface effectively, hence giving a little space for heat generation on the tool rake face.

Fortunately, the efficiency of the LN cooling ability to reduce the temperature at the primary and tertiary deformation zones helps in reducing the accumulative heat that is transferred to the tool. The temperature contours shown in Fig. $3 \mathrm{~b}$ clearly prove that the heat generated at the primary and tertiary deformation zones in the cryogenic machining is much lower than that in the dry cutting as illustrated in Fig. 3 a.

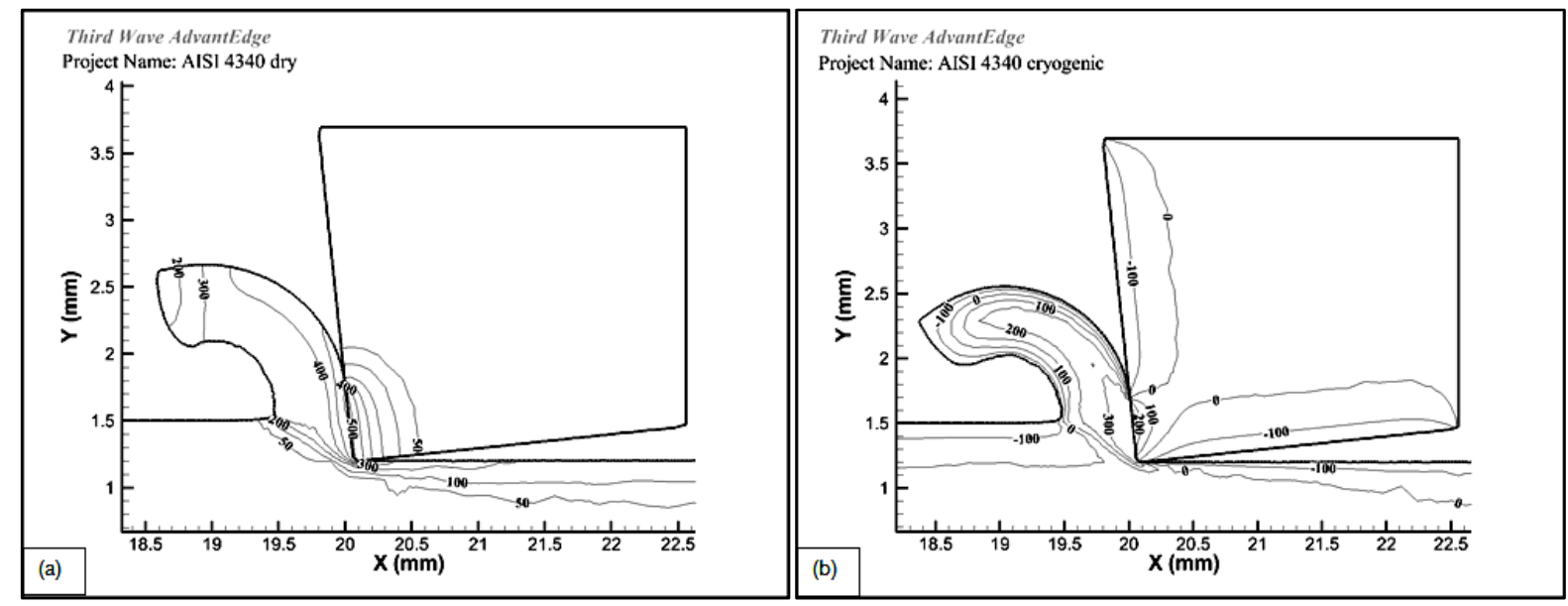

Figure 3: Comparison of temperature gradient distribution in a) dry and b) cryogenic turning of AISI 4340 using AdvantEdge simulation.

The temperature contour distributions over the distance on the rake and flank face area of the tool was plotted in the graph generated by the AdvantEdge software as shown in Fig. 4. It can be seen from both Figs. 3 and 4 that the temperature at the very tip of the tool, which is indicated as $0 \mathrm{~mm}$ distance on the $\mathrm{x}$-axes in Fig. 4, is very low with the application of $\mathrm{LN}$, falling in the contour region of $0-50{ }^{\circ} \mathrm{C}$, as compared to the dry cutting condition that generated a very high temperature in the contour region of $500-600^{\circ} \mathrm{C}$ at the tip of the insert. Consequently, a larger "hot spot" area was developed on the tool edge up to the tool rake face in the dry cutting, making the edge became a heat sink and overheat [18]. This will be a contributing factor to crater wear progression.

As for the flank face region, it is predicted that in dry cutting, the temperature can still be elevated to higher than $400{ }^{\circ} \mathrm{C}$ over a portion of the tool flank face close to the cutting edge, an area where the flank wear occurs as the tool-workpiece contact develops. Therefore, when reaching these temperatures in the dry cutting of the AISI 4340, a high tool wear rate can be expected on both the tool rake and the tool flank [19]. Meanwhile, in cryogenic turning, the temperature on the flank face region near to the cutting edge is expected to be less than $0{ }^{\circ} \mathrm{C}$. This low temperature is beneficial in increasing the hardness of the tool material, hence resulting in a lower tool wear rate. 


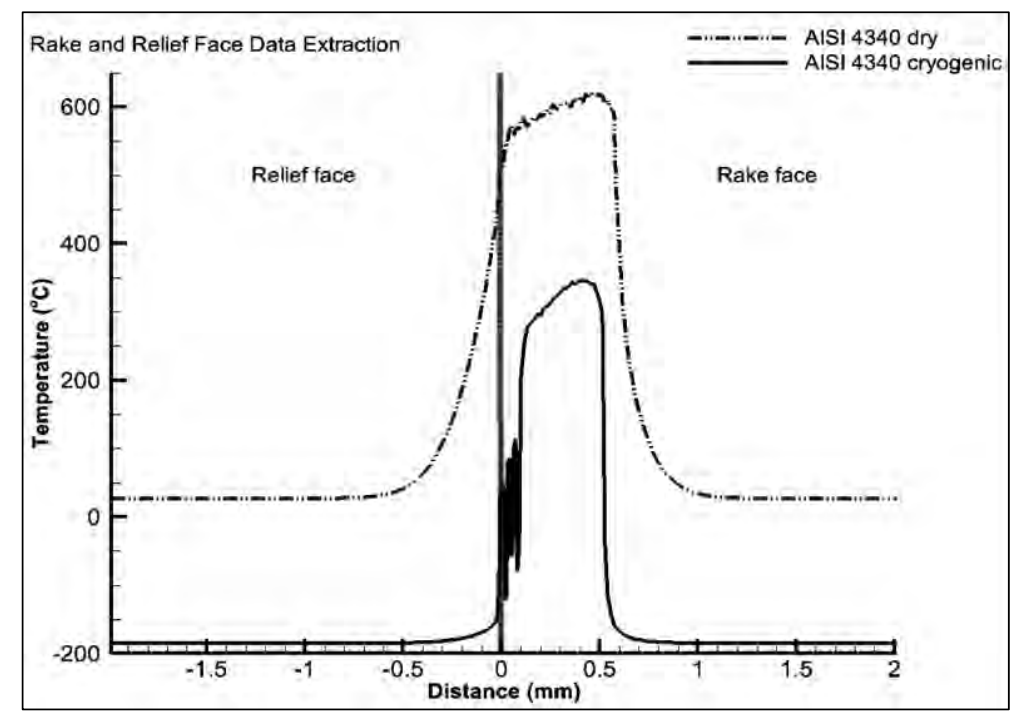

Figure 4: Rake and relief face temperature data extraction in dry and cryogenic turning of AISI 4340.

Fig. 5 presents the differences between the predicted temperatures generated in the finite element simulation and the temperatures measured by the NEC thermal infrared camera during the actual cutting process. The low percentage difference between the FE and measured temperature which is between $5 \%-7 \%$ proved that the value of calculated $h$ is reliable. The bar chart clearly shows a drop of $32 \%-33 \%$ in the temperature when machining with LN.

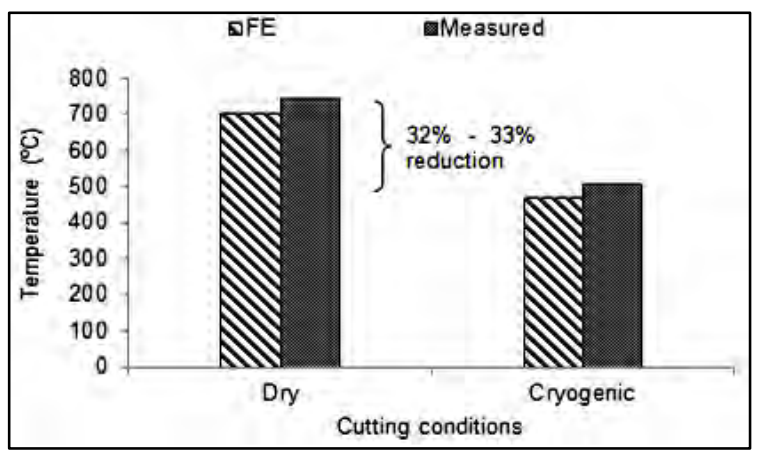

Figure 5: Measured and predicted cutting temperatures in dry and cryogenic turning of AISI 4340.

The chips formed in both tests were further analysed through close observation under a stereo microscope. The validation and relation of the temperature contour distribution from the simulation results with the real chips were found through a comparison of the chips' shape and size. A comparison of the detail analysis of the debris of the dry and cryogenic turnings, such as the chip thickness, and the calculated shear angle and coefficient of friction can be found in [16]. Fig. 6 below shows the comparison of the chip's shape and the degree of chip's curl in the dry and cryogenic turnings of the AISI 4340 in the experimental and simulation runs.

In Fig. 6 a, it can be seen that the chips produced in the cryogenic turning are curlier than those produced in the dry turning. This is also supported by the Third Wave simulation results shown in Fig. $6 \mathrm{~b}$. The temperature difference that occurred at the upper side and the underside of the chips, as labelled in Fig. 6 b, determines the degree of the chip's curl. The larger the temperature difference, the curlier the chip. As shown in Fig. 3 previously, the temperature difference between the upper side and the underside of the chips in the cryogenic turning was larger compared to the dry turning. This is most probably due to the direct 
exposure of the upper side of the chips to the low temperature of the cryogenic coolant, hence making the heat removal process of that zone more effective. This results in a steeper temperature gradient across the chip and varies the degree of material contraction on the upper side and the underside of the debris due to the different temperature values. Consequently, tighter chip curl and shorter chip-tool contact length are produced in the cryogenic turning [18]. A shorter contact length is favourable due to several reasons. It is claimed to be able to reduce the tool wear, especially crater wear [18], besides assisting the entrainment of the LN into the primary deformation zone and act as a coolant and lubricant more effectively. The reduction in contact length between chip-tool interfaces in the cryogenic turning is also proven in the simulation, as shown in Fig. 7. The difference in the shear plane length is also marked in the figure where it is clearly shown that the contact length and shear plane length is longer in the dry turning compared to the cryogenic turning.
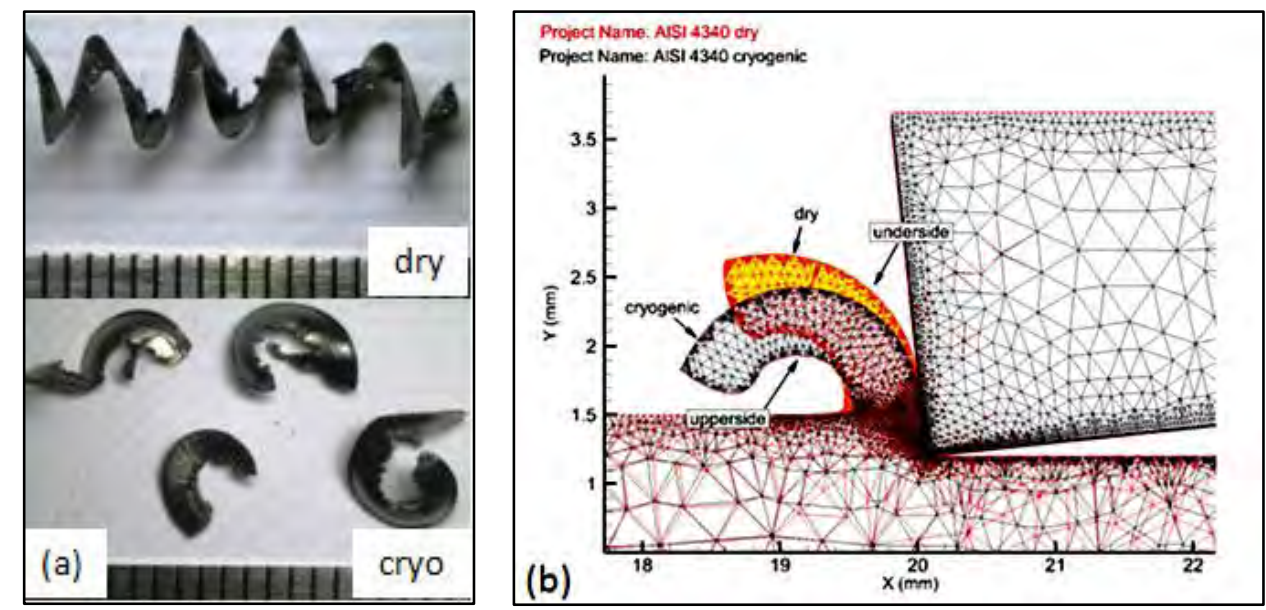

Figure 6: Comparison of chip's shape and the degree of chip's curl in dry and cryogenic turnings of AISI 4340 alloy steel in a) experimental test $(6.7 \times$ magnification $)$ and b) FE simulation.
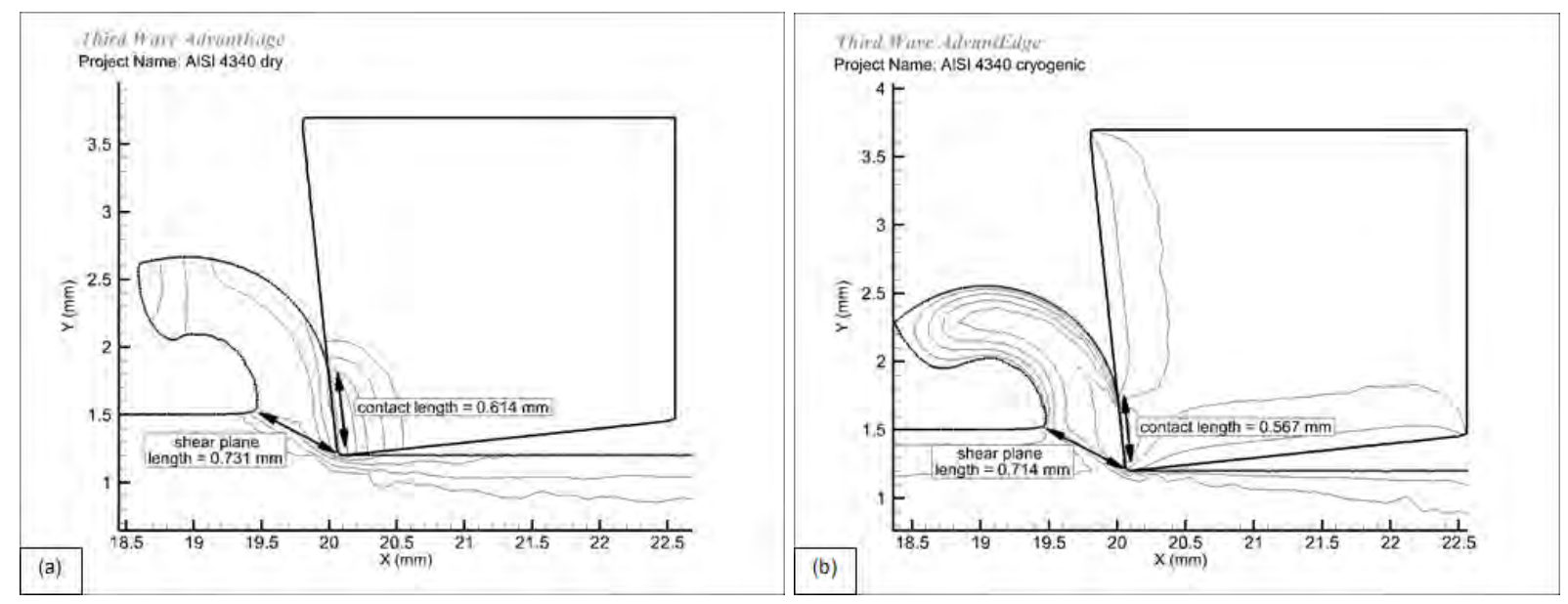

Figure 7: Comparison of shear plane length and contact length in a) dry and b) cryogenic turnings of AISI 4340 using AdvantEdge simulation.

The discontinuous type of chips produced in the cryogenic turning was a consequence of hardness and brittleness increment [20], as well as the weakened welded junctions between the chips [21] due to the low temperature at the primary deformation zone as shown in Fig. 3. Hence, it can be concluded that cryogenic turning improves the chip breakability during machining. This will facilitate deeper penetration of the LN into the cutting zone, thus enhancing the lubricating and cooling function of the coolant. In Fig. 6, it can be seen that the cryogenic turning produced a short and discontinuous type of chips, while the dry turning 
resulted in longer and continuous chips caused by the ductility of the chips resulting from the high interface temperature [22]. In addition, the results discussed in [16] revealed that the chips produced in the cryogenic turning were thinner compared to those produced in the dry turning, which is due to the lubricating property of the LN. This factor might also be the reason for the enhancement of chip breakability [23].

Fig. 8 presents the predicted and measured cutting forces which show the decrement of the cutting force $\left(f_{x}\right)$ and feed force $\left(f_{y}\right)$ during the cryogenic machining as compared to the dry turning. The chips produced in the cryogenic turning have a more apparent serrated sawtooth appearance, which indicates an increment of hardness of the chip material. Meanwhile, the debris produced in the dry turning was wavy transitional chips with shared characteristics of both continuous and segmented sawtooth chip types. The increment of the hardness and brittleness of the chip material caused by the low LN temperature makes it require smaller fracture energy to break during the machining operation, hence reducing the cutting force [24]. The percentage difference between the measured and predicted cutting force is between $0.8 \%-12 \%$.

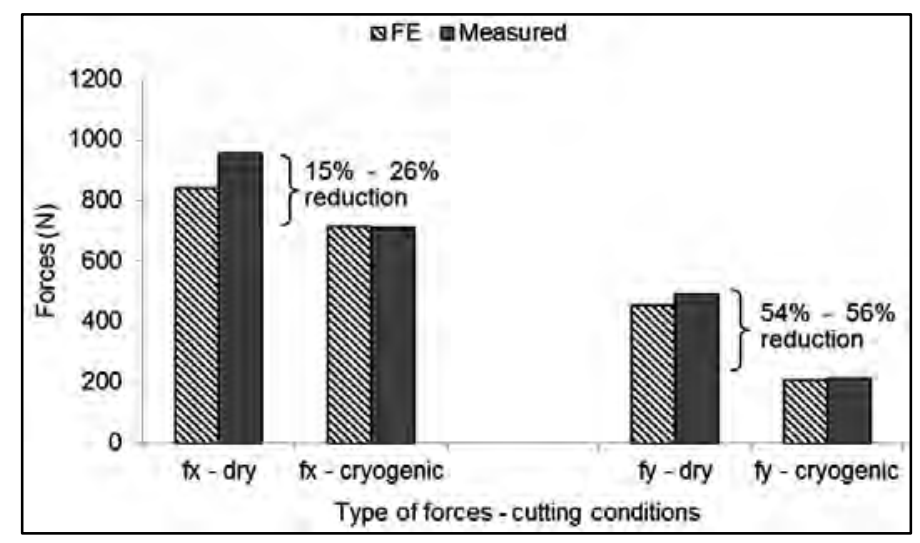

Figure 8: Measured and predicted cutting forces in dry and cryogenic turning of AISI 4340.

The average roughness of the cryogenic machined surface improved by about $11 \%$ compared to the dry turning, as shown in Fig. 9. Bad surface finish in the dry cutting is most probably due to the adhesive effects at the workpiece-tool interface caused by the high temperature [5]. Besides, the phenomenon of flank build-up, built-up edge, or even a dead metal zone that usually forms at the edge of the radius of the insert [25], which are commonly associated with high cutting temperatures, might also contribute to the high surface roughness. The application of the $\mathrm{LN}$ which effectively reduced the cutting temperature, lessened all the effects mentioned above.

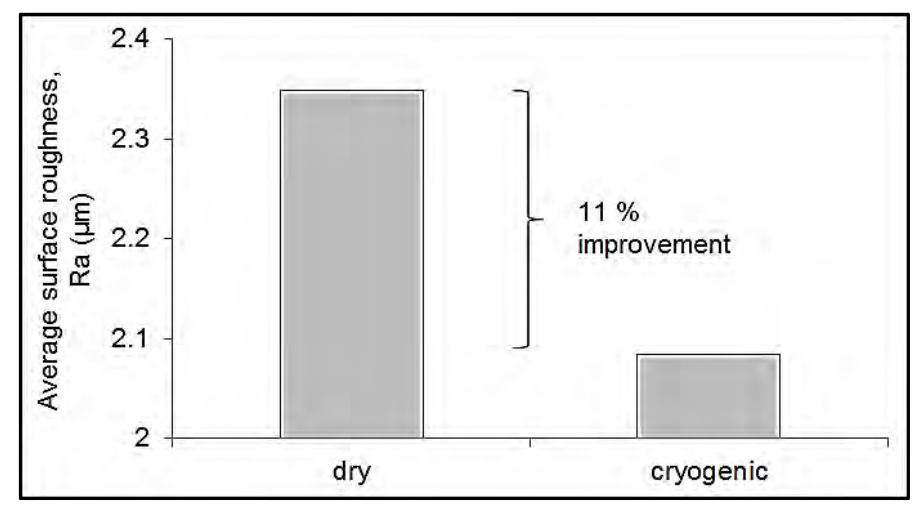

Figure 9: Average surface roughness in dry and cryogenic turnings of AISI 4340. 


\section{CONCLUSION}

This paper has provided empirical validation of the tribological effect of LN application during a machining process on the temperature generated at the tool-chip interface, compared to dry cutting, in the turning of AISI 4340 alloy steel using a coated carbide tool through FEA simulation and experimental tests. The commercial FEA software, Third Wave AdvantEdge was used in this research to serve the purpose of predicting the machining outputs in this metal cutting process. Temperature distribution contours on the chip and tool, the shape and types of chips produced, as well as the cutting forces generated during the cutting operation were compared between the simulated results and the experimental results. A number of tentative conclusions can be drawn:

- The application of LN in the cryogenic machining has effectively reduced the temperature in three critical heat source zones in the metal cutting, namely, the primary deformation zone occurring at the shear plane, the secondary deformation zone at the chip-tool interface, and lastly, the tertiary deformation zone at the tool-work piece interface, which is favourable for reducing the flank wear progression. A $32 \%-33 \%$ temperature decrement in the cryogenic machining, compared to the dry turning, has been observed both in FE simulation and experimental tests.

- The formation of a "hot spot" area on the tool's rake face resulting from the accumulated heat being transferred from the three heat sources to the tool, was smaller with much lower temperature in the cryogenic turning compared to the dry turning. This may help to improve the crater wear progression on the tool's rake face.

- The chips produced in the cryogenic turning were discontinuous, shorter and curlier compared to those obtained in the dry turning. This indicates a shorter chip-tool contact length and shear plane length in the cryogenic turning and an enhanced chip breakability.

- The formation of a more apparent serrated sawtooth type of chips in the cryogenic turning indicates that there was a decrease of the machining forces as proven by a $15 \%-26 \%$ reduction of the cutting forces, and $54 \%-56 \%$ feed forces, in both the simulation and real experimental tests. This implies that LN also provides better lubrication during machining.

The significant reduction in the cutting temperature and machining forces obtained in the cryogenic turning as verified in both simulation and experimental results indicate an effective heat removal from the cutting zone and efficient lubrication performed by the LN. The combination of a steeper temperature gradient and lower temperature generated at the cutting edge provides the advantages of a longer tool life, better surface finish, and a reduction of the friction coefficient. Moreover, small percentage difference between the measured value and predicted value by the FEA for both cutting temperature and cutting forces proved that the calculated value oh heat transfer coefficient being used in this research is reliable.

\section{REFERENCES}

[1] Abukhshim, N. A.; Mativenga, P. T.; Sheikh, M. A. (2006). Heat generation and temperature prediction in metal cutting: A review and implications for high speed machining, International Journal of Machine Tools \& Manufacture, Vol. 46, No. 7-8, 782-800, doi:10.1016/ j.ijmachtools.2005.07.024

[2] Meyer, D. (2012). Cryogenic deep rolling - An energy based approach for enhanced cold surface hardening, CIRP Annals - Manufacturing Technology, Vol. 61, No. 1, 543-546, doi:10.1016/ j.cirp.2012.03.102

[3] Umbrello, D.; Micari, F.; Jawahir, I. S. (2012). The effects of cryogenic cooling on surface integrity in hard machining: A comparison with dry machining, CIRP Annals - Manufacturing Technology, Vol. 61, No. 1, 103-106, doi:10.1016/j.cirp.2012.03.052 
[4] Pusavec, F.; Hamdi, H.; Kopac, J.; Jawahir, I. S. (2011). Surface integrity in cryogenic machining of nickel based alloy - Inconel 718, Journal of Materials Processing Technology, Vol. 211, No. 4, 773-783, doi:10.1016/j.jmatprotec.2010.12.013

[5] Pu, Z.; Outeiro, J. C.; Batista, A. C.; Dillon Jr, O. W.; Puleo, D. A.; Jawahir, I. S. (2012). Enhanced surface integrity of AZ31B Mg alloy by cryogenic machining towards improved functional performance of machined components, International Journal of Machine Tools \& Manufacture, Vol. 56, 17-27, doi:10.1016/j.ijmachtools.2011.12.006

[6] Xavier, S. E. D.; Delijaicov, S.; De Farias, A.; Filho, M. S.; Batalha, G. F. (2010). Investigation on the surface integrity and tool wear in cryogenic machining, International Conference on Advances in Materials and Processing Technologies, 1199-1205

[7] Bermingham, M. J.; Palanisamy, S.; Kent, D.; Dargusch, M. S. (2012). A comparison of cryogenic and high pressure emulsion cooling technologies on tool life and chip morphology in Ti-6Al-4V cutting, Journal of Materials Processing Technology, Vol. 212, No. 4, 752-765, doi:10.1016/j.jmatprotec.2011.10.027

[8] Panigrahi, S. K.; Jayaganthan, R. (2005). Development of ultrafine grained high strength age hardenable Al 7075 alloy by cryorolling, Materials \& Design, Vol. 32, No. 6, 3150-3160, doi:10.1016/j.matdes.2011.02.051

[9] Chou, Y. K.; Song, H. (2005). Thermal modeling for white layer predictions in finish hard turning, International Journal of Machine Tools \& Manufacture, Vol. 45, No. 4-5, 481-495, doi:10.1016/j.ijmachtools.2004.09.006

[10] Warren, A. W.; Guo, Y. B. (2006). Machined surface properties determined by nanoindentation: Experimental and FEA studies on the effects of surface integrity and tip geometry, Surface \& Coatings Technology, Vol. 201, No. 1-2, 423-433, doi:10.1016/j.surfcoat.2005.11.139

[11] Hong, S. Y.; Ding, Y.; Ekkens, R. G. (1999). Improving low carbon steel chip breakability by cryogenic chip cooling, International Journal of Machine Tools \& Manufacture, Vol. 39, No. 7, 1065-1085, doi:10.1016/S0890-6955(98)00074-1

[12] Tamizharasan, T.; Senthil Kumar, N. (2012). Optimization of cutting inserts geometry using DEFORM-3D: Numerical simulation and experimental validation, International Journal of Simulation Modelling, Vol. 11, No. 2, 65-76, doi:10.2507/IJSIMM11(2)1.200

[13] Davoudinejad, A.; Chiappini, E.; Tirelli, S.; Annoni, M.; Strano, M. (2015). Finite element simulation and validation of chip formation and cutting forces in dry and cryogenic cutting of Ti-6Al-4V, Procedia Manufacturing, Vol. 1, 728-739, doi:10.1016/j.promfg.2015.09.037

[14] Pu, Z.; Umbrello, D.; Puleo, D. A.; Dillon Jr, O. W.; Lu, T.; Jawahir, I. S. (2013). Finite element modeling of microstructural changes in dry and cryogenic machining of AZ31B magnesium alloy for enhanced corrosion resistance, Proceedings of NAMRI/SME, Vol. 41, 10 pages

[15] Hong, S. Y.; Ding, Y. (2001). Micro-temperature manipulation in cryogenic machining of low carbon steel, Journal of Materials Processing Technology, Vol. 116, No. 1, 22-30, doi:10.1016/ S0924-0136(01)00836-6

[16] Natasha, A. R.; Ghani, J. A.; Syarif, J.; Haron, C. H. C.; Hadi, M. A. (2014). Comparison of dry and cryogenic machining on chip formation and coefficient of friction in turning AISI 4340 alloy steel, Applied Mechanics and Materials, Vol. 554, No. 7, 7-11, doi:10.4028/www.scientific.net/ AMM.554.7

[17] Daniel, C. M.; Rao, K. V. C.; Olson, W. W.; Sutherland, J. W. (1996). Effect of cutting fluid properties and application variables on heat transfer in turning and boring operations, Japan/USA Symposium on Flexible Automation, Vol. 2, 1119-1126

[18] Stanford, M.; Lister, P. M.; Morgan, C.; Kibble, K. A. (2009). Investigation into the use of gaseous and liquid nitrogen as a cutting fluid when turning BS 970-80A15 (En32b) plain carbon steel using WC-Co uncoated tooling, Journal of Materials Processing Technology, Vol. 209, No. 2, 961-972, doi:10.1016/j.jmatprotec.2008.03.003

[19] Hong, S. Y.; Ding, Y. (2001). Cooling approaches and cutting temperatures in cryogenic machining of Ti-6Al-4V, International Journal of Machine Tools \& Manufacture, Vol. 41, No. 10, 1417-1437, doi:10.1016/S0890-6955(01)00026-8

[20] Hong, S. Y.; Ding, Y.; Jeong, W.-C. (2001). Friction and cutting forces in cryogenic machining of Ti-6Al-4V, International Journal of Machine Tools \& Manufacture, Vol. 41, No. 15, 22712285, doi:10.1016/S0890-6955(01)00029-3 
[21] Kumar, K. V. B. S. K.; Choudhury, S. K. (2008). Investigation of tool wear and cutting force in cryogenic machining using design of experiments, Journal of Materials Processing Technology, Vol. 203, No. 1-3, 95-101, doi:10.1016/j.jmatprotec.2007.10.036

[22] Deng, W. J.; Xie, Z. C.; Li, Q.; Lin, P. (2013). Finite element modelling and simulation of chip breaking with grooved tool, International Journal of Simulation Modelling, Vol. 12, No. 4, 264275, doi: $10.2507 / \operatorname{IJSIMM12(4)5.250}$

[23] Jerold, B. D.; Kumar, M. P. (2011). Experimental investigation of turning AISI 1045 steel using cryogenic carbon dioxide as the cutting fluid, Journal of Manufacturing Processes, Vol. 13, No. 2, 113-119, doi:10.1016/j.jmapro.2011.02.001

[24] Luo, S. Y.; Liao, Y. S.; Tsai, Y. Y. (1999). Wear characteristics in turning high hardness alloy steel by ceramic and CBN tools, Journal of Materials Processing Technology, Vol. 88, No. 1-3, 114-121, doi:10.1016/S0924-0136(98)00376-8

[25] Wan, L.; Wang, D.; Gao, Y. (2015). Investigations on the effects of different tool edge geometries in the finite element simulation of machining, Strojniski vestnik - Journal of Mechanical Engineering, Vol. 61, No. 3, 157-166, doi:10.5545/sv-jme.2014.2051 